\title{
Sensor System: A Survey of Sensor Type, Ad Hoc Network Topology and Energy Harvesting Techniques
}

\author{
Phuoc Duc Nguyen (1) and Lok-won Kim* \\ Computer Science and Engineering Department, Kyung Hee University, Global Campus, Yongin 17104, Korea; \\ phuocdn@khu.ac.kr \\ * Correspondence: lwk@khu.ac.kr; Tel.: +82-31-201-2547
}

check for updates

Citation: Nguyen, P.D.; Kim, L.-w. Sensor System: A Survey of Sensor Type, Ad Hoc Network Topology and Energy Harvesting Techniques. Electronics 2021, 10, 219. https:// doi.org/10.3390/electronics10020219

Received: 15 December 2020 Accepted: 12 January 2021 Published: 19 January 2021

Publisher's Note: MDPI stays neutral with regard to jurisdictional clai$\mathrm{ms}$ in published maps and institutional affiliations.

Copyright: (C) 2021 by the authors. Licensee MDPI, Basel, Switzerland. This article is an open access article distributed under the terms and conditions of the Creative Commons Attribution (CC BY) license (https:// creativecommons.org/licenses/by/ $4.0 /)$.

\begin{abstract}
People nowadays are entering an era of rapid evolution due to the generation of massive amounts of data. Such information is produced with an enormous contribution from the use of billions of sensing devices equipped with in situ signal processing and communication capabilities which form wireless sensor networks (WSNs). As the number of small devices connected to the Internet is higher than 50 billion, the Internet of Things (IoT) devices focus on sensing accuracy, communication efficiency, and low power consumption because IoT device deployment is mainly for correct information acquisition, remote node accessing, and longer-term operation with lower battery changing requirements. Thus, recently, there have been rich activities for original research in these domains. Various sensors used by processing devices can be heterogeneous or homogeneous. Since the devices are primarily expected to operate independently in an autonomous manner, the abilities of connection, communication, and ambient energy scavenging play significant roles, especially in a large-scale deployment. This paper classifies wireless sensor nodes into two major categories based the types of the sensor array (heterogeneous/homogeneous). It also emphasizes on the utilization of ad hoc networking and energy harvesting mechanisms as a fundamental cornerstone to building a self-governing, sustainable, and perpetually-operated sensor system. We review systems representative of each category and depict trends in system development.
\end{abstract}

Keywords: sensor system; heterogeneous; homogeneous; ad hoc; energy harvesting

\section{Introduction}

Wireless sensor nodes with sensing, computing, and communication capabilities play an integral role in a highly connected world, where data are generated in tremendous volumes at an extremely rapid rate. That is one of the reasons that motivates researchers to pay close attention to detail and to expend tremendous effort toward the development of such devices. Current tendencies in the development of sensor nodes require not only the utilization of appropriate sensor types for the problem of interest, but also the proper usage of the right strategies for signal processing and communication. Furthermore, the ability to operate autonomously and efficiently with an energy harvesting mechanism is also much demanded. This paper aims to identify the challenges of building such systems and paves the way for researchers to create an automated and perpetually-operated wireless sensor node.

The world population in 2020, according to the United Nations [1], is approximately 7.8 billion. As reported by NCTA (The Internet and Television Association) in Figure 1, at the inception of the IoT in 2009, the number of small electronic devices connected to the Internet was around 5 billion. With in a decade, the device volume experienced a rapid increase with an exponential rate of change. By 2020, the number of IoT devices has been estimated at more than 50 billion. The quantity of connected devices will become ten times higher than the number of people on the planet in the coming years. With an enormous number of devices, along with huge masses of data generated, many research activities 
and efforts have been spent on creating efficient and effective IoT hardware systems where sensors, communications, and energy efficiency play important roles in providing the necessary information about various physical quantities. Therefore, it is necessary to have an overview of the technology involved in the data acquisition, processing, transmission, and power management to create prosperous IoT hardware platforms that can perform efficiently, with environmental friendliness, and with long term usage.

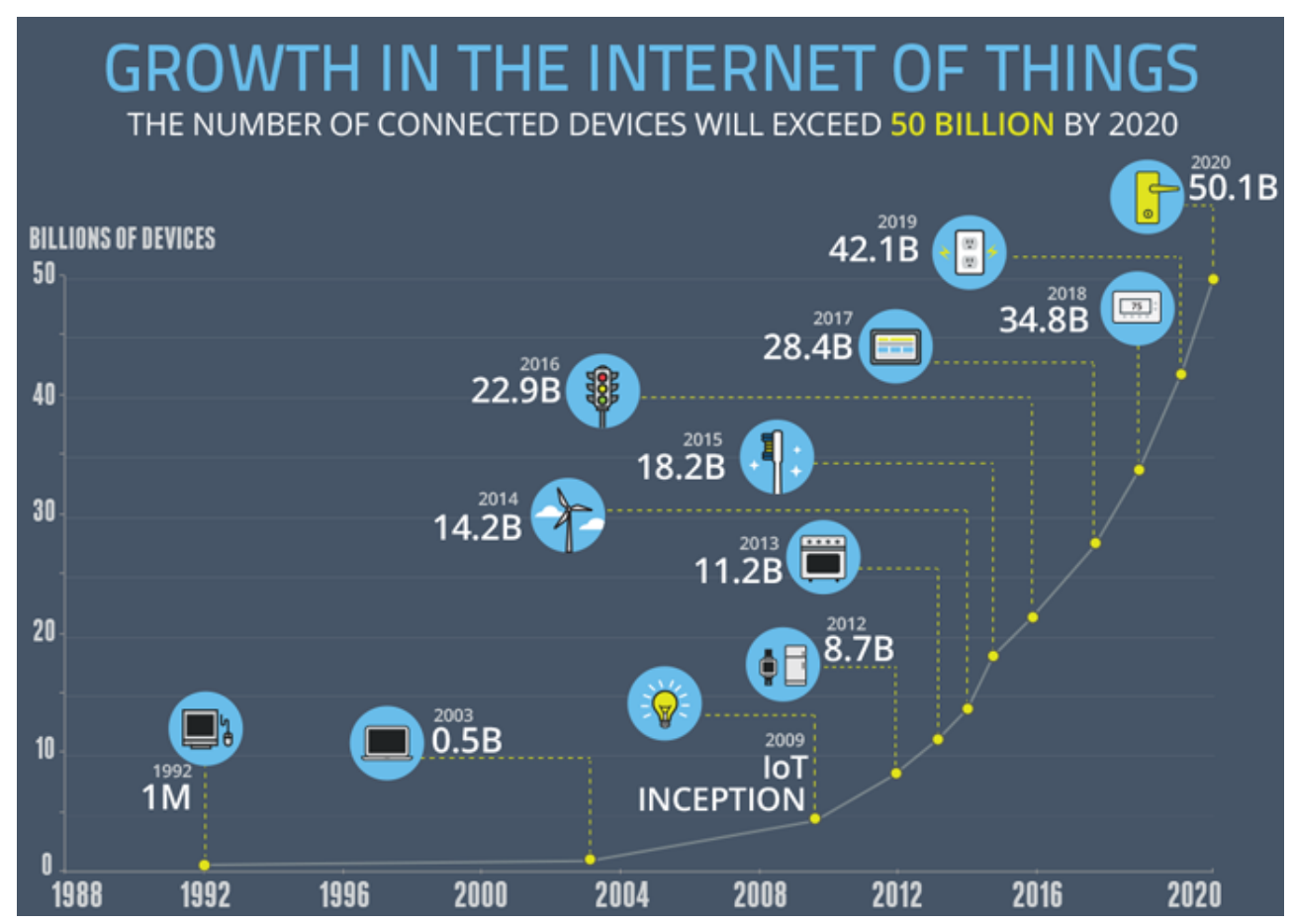

Figure 1. The population growth of the Internet of Things [2].

System characteristics are analyzed and identified based on the type of sensors used, how they are connected to form a network, and how their power is managed and maintained. The selection of sensor types, whether heterogeneous or homogeneous, has a strong effect on processing capabilities, the communication structure, and the total power usage. The application's nature places most of the constraints on the sensor type choice. If a wireless sensor node uses only one type of sensor, it is classified as a system with homogeneous sensors. Otherwise, the node falls into the array of the heterogeneous sensor category. Depending on how measurements are conducted, users can decide to opt for one or the other. For example, if the application requires one measurement quantity only and needs a wide coverage, a system with a homogeneous sensor array is an appropriate selection. If an application, on the other hand, needs a balance in measurements from various entities to compensate for each other, the suitable choice is to go with a heterogeneous sensor system. After in situ data aggregation and processing, the node needs to send the processed data through wireless communication. An appropriate node placement strategy of the network helps save bandwidth and facilitates data processing scheme. An ad hoc network where nodes can be dynamically and easily deployed is a decent network topology for WSNs. Energy affects every aspect of the node's operation. Hence, in order to have a sustainable and environmentally friendly solution, an energy harvesting mechanism needs to be incorporated and integrated into the design of the wireless sensor node. The dynamic changes of the environment after the system's deployment call for an adaptable mechanism, and that is the reason why machine learning is gaining more traction these days. Various machine learning algorithms are exploited in system design, ad hoc networking, and energy harvesting to improve performance.

The rest of the paper is structured as follows: Section 2 discusses the characteristics of systems with respective heterogeneous and homogeneous sensor arrays. Next, the features 
and challenges of the ad hoc network are presented in Section 3, along with viable solutions. Section 4 explores the possibility of constructing a long-life operation system through examining energy harvesting techniques. Section 5 summarizes the features discussed in the previous sections and assesses systems that possess all the features. The last section concludes the paper with remarks.

\section{Wireless Sensor System}

Each wireless sensor node typically performs three main functions-sensing, processing, transceiving data, along with optionally issuing commands to actuators (Figure 2). The sensing tasks cannot be done without sensors attached. To the best of our knowledge, there has not been any review paper for wireless sensor networks that classify sensor nodes based on their sensor type. We divide the sensors used in a wireless sensor node into two categories: heterogeneous if a node system uses sensors of various types and homogeneous if a system only utilizes only one kind of sensor. A wireless sensor node utilizes sensors for examining various aspects in the surrounding environments, and then uses the main computing unit for handling plenty of signal processing tasks. The heavy lifting jobs can be managed by many types of processing: a microcontroller unit (MCU), digital signal processing (DSP), a field-programmable gate array (FPGA), or combinations of them (Figure 3). The decision on which platform to use depends on the requirements-whether the application needs a higher performance or it demands greater flexibility in terms of usage. In the case of a large amount of data being generated, the application of machine learning in sensor systems is inevitable. The increasing usage of machine learning integrated into the processing unit makes the system adaptable to dynamic changes. However, it requires significant effort to embed a lightweight algorithm into a constrained system. Therefore, researchers are making active attempts at smooth combinations of machine learning algorithms and sensor systems. Not only running in situ processing, the nodes are also capable of sending data through networks or receiving commands to actuate on environments. Sensors in use can be of the same type or different types depending on the requirements of the problem. A heterogeneous sensor type is suitable in applications that require extensive details, while a homogeneous sensor type is relevant to applications with the need for a wide range of and accurate measurements.

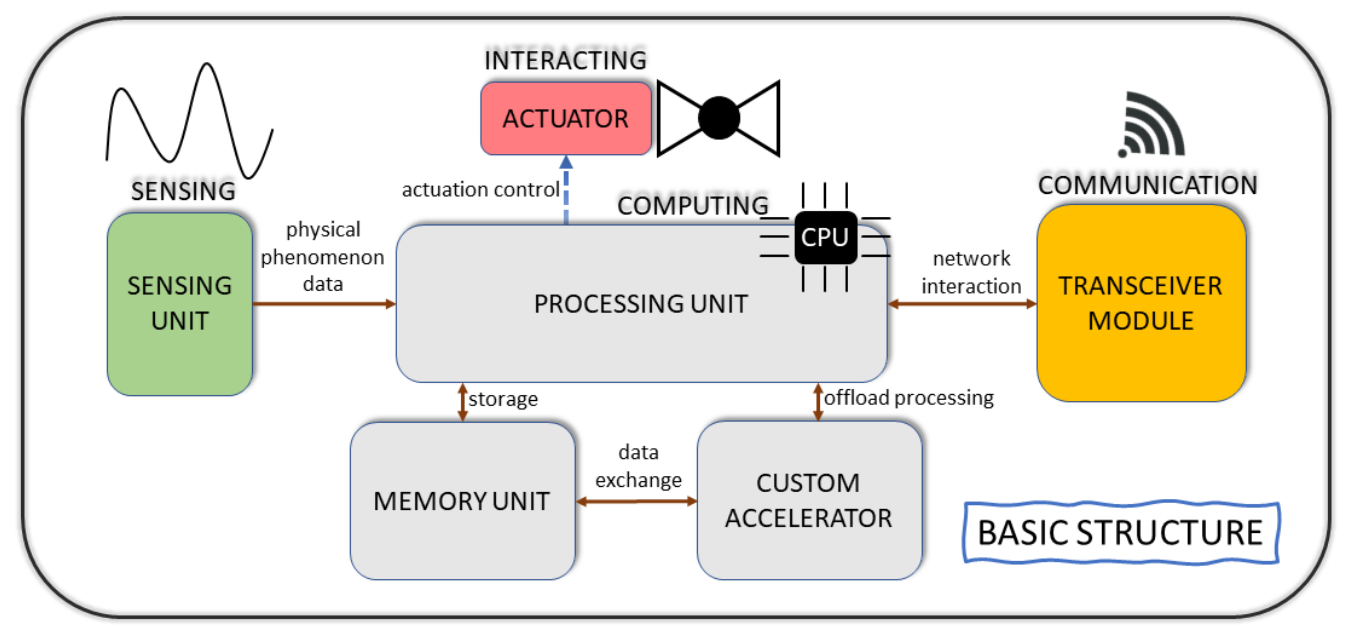

Figure 2. Basic structure of a sensor node (adapted from $[3,4]$ ). 


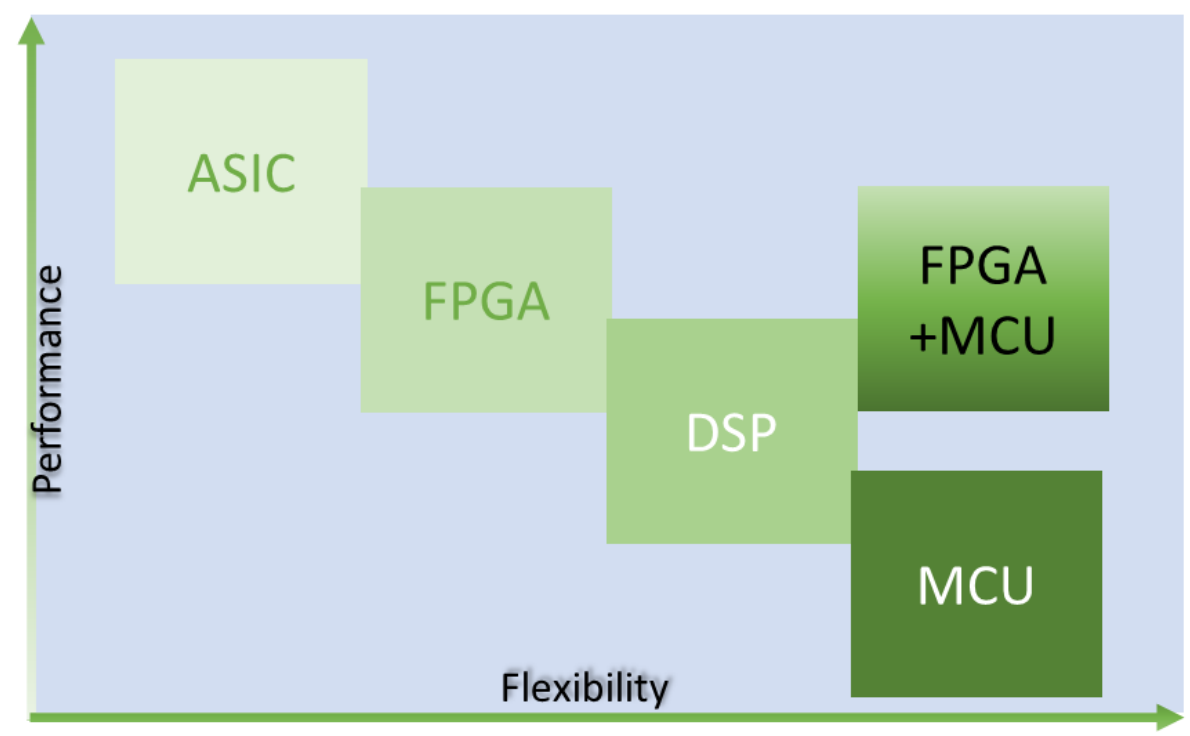

Figure 3. Different processing platforms (adapted from [5]).

\subsection{Heterogeneous Sensor System}

Systems using heterogeneous sensor arrays are widely used in various applications, such as environmental sensing, health tracking, and structural monitoring. Several control actions need to synthesize and analyze data from various perspectives in order to make a joint decision. For example, in agriculture, a wireless sensor node operating on volumetric water content needs to collect information from the ambient temperature and plant moisture [6]. Therefore, it inherently requires two types of sensors: temperature and moisture sensors. In some other cases, the natural diversification of properties simply renders a single sensor type unqualified to the application, thereby facilitating the use of heterogeneous sensors. For instance, in autonomous driving, each sensing device has its own diversification on the accuracy, while the road traversing action requires more intelligence to make a correct decision. Another group of situations that requires multiple types of sensors is medical and health care services where individual sensors have various data rates (Figure 4).

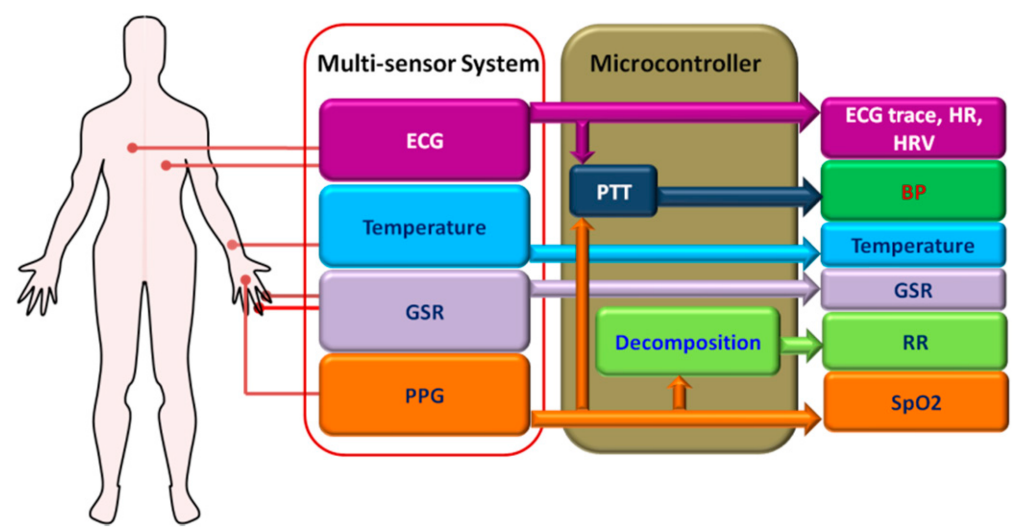

(a)

Figure 4. Cont. 


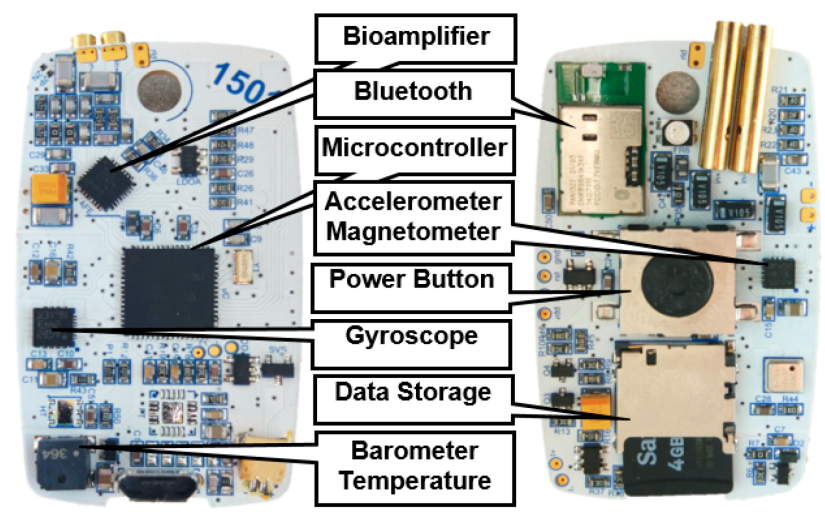

(b)

Figure 4. Usage of heterogeneous sensor systems: (a) A system utilizing ECG (electrocardiogram), temperature, GSR (galvanic skin response), and PPG (photo-plethysmograph) sensors [7]. (b) A system utilizing an accelerometer, a magnetometer, a gyroscope, a barometer, and a temperature sensor [8].

A single sensor has limitations in level of detail, such as limited spatial and temporal coverage or uncertainty of measurement data when some features are missing [9]. As pointed out in [10], a camera has a limitation in the detection range, and radar does not consistently give accurate readouts. Despite giving precise data collection and accuracy, lidar's performance can be highly affected by environmental factors, such as rain, clouds, and the sun. Sonar can deliver information about nearby objects but has a short sensing range. Therefore, the authors in $[9,10]$ have proposed a multi-sensor system to assist the autonomous driving functionality. In [11], a system with heterogeneous sensors was proposed for the detection of partial discharge. It utilized various sensor types, such as piezoelectric, light, and temperature to obtain more features for the detection task while lowering the detection threshold. The flow of diverse data coming from different types of sensors requires a data fusion procedure for the data processing stage. Furthermore, a customized sensor needs to be designed to accommodate application requirements on some occasions. A custom-made sensor design helps overcome drawbacks present in the current operation [12] or augment and incorporate some more functionalities into the sensors, making the design more tailored and adaptable [13]. The sensor system from [14] exhibits a good model for a design with a customized sensor and fusion algorithms. The system was applied to contamination detection in a water distribution system. Several important physicochemical parameters were determined through extensive evaluations and by various drinking water quality standards. After the analysis, five parameters, including $\mathrm{pH}$, oxidation reduction potential (ORP), turbidity (TU), electrical conductivity (EC), and temperature $(\mathrm{T})$, were chosen based on their reliability and performance in continuous monitoring of water quality. A custom-made turbidity sensor was developed using a ratio turbidimeter design. The developed turbidity sensor had satisfactory characteristics, such as low cost, ease of use, and the desired level of accuracy, making it preferable over offthe-shelf components. All chosen sensors were accompanied by a calibration procedure to obtain linear responses and high accuracies. Each sensor's data went into a PIC controller where data fusion and contamination detection algorithms were used. Processed data were then transmitted wirelessly through a ZigBee 3G/GPRS (General Packet Radio Service) module to a notification node for immediate actions at the local site or to a control node for access over the Internet and real time monitoring. The detection of contamination events was expressed by two algorithms: the vector distance algorithm (VDA) and the polygon area algorithm (PAA). The computations also performed the multi-sensor measurement fusion for TU, ORP, $\mathrm{pH}$, and EC. Sensor measurement outputs were required to be normalized using sensor parameters over a specific monitoring time. The two algorithms expected statistical values such as the mean and standard deviation of sensor measurements over a certain time range along with a sensor parameter to obtain normalized sensor outputs. 
The detection algorithms formulated the risk of water contamination based on normalized sensor signal vectors. Experiments were set up to assess the hardware performance along with the software's effectiveness in contamination detection. Two types of controlled injection were performed: one for microbiological contamination using Escherichia coli and one for chemical contamination using Arsenic. In both cases, the system responded with satisfactory results, and one algorithm (PAA) outperformed the other in terms of performance and amount of information utilization.

Besides using traditional MCUs as the main processing units, some applications demand high-speed processing. Thus, other types of processing engines can be used, such as DSP or FPGA. Ledeczi et al. [15] proposed a wireless detection system for fatigue cracks in railways bridges. The system featured appreciative characteristics, such as low cost and easy deployment, in contrast to using costly and cumbersome long-cable systems. Furthermore, the suggested system is favored over a visual inspection due to the useful assessment based on various parameters related to the fracture of the infrastructure. The system fulfilled the functional and non-functional requirements of the structural monitoring problem through various means: by utilizing a high number of sensors for large coverage, exploiting lightweight energy storage and energy harvesting to eliminate the need for a constant power source, removing lengthy wires by wireless communication, and facilitating high volume deployment with low cost components. The system utilized an array of heterogeneous sensors with a four-channel acoustic emissions (AE) sensor and a strain gauge. Multiple AE channels were used to filter out noise in the bridge system, providing consistent observations. Due to the high demand for power and the presence of crack-related acoustic emissions when a train moved across the bridge, AE sensors were not active all the time. The strain gage, therefore, acted as a trigger for the whole system, realizing when a moving object was coming, and it would wake up other parts in the system accordingly. This approach reduced a large amount of power consumption and lengthened the system's lifetime for one battery charge by up to six weeks. Due to insufficient computing resources in low-power DSP chips, the system used the FPGA as the main computation engine. The FPGA facilitated streaming signal processing, eliminating the demand for signal buffers and increasing the sampling speed. The FPGA-based system performed high-speed samplings and various signal processing tasks, such as feature extraction and source localization. The authors analyzed various aspects of AE events stemming from a bridge rift, such as patterns in the waveform and conspicuous signal features that could tell the difference between events of interest and noise. Two criteria for the AE data evaluation were activity and intensity. The activity was interpreted as acoustic events recognized by all AE sensors with three levels: inactive, active, and critically active, where the peak load constant occurred. The intensity was characterized as the average value of the acoustic event magnitude. Four degrees of intensity were introduced: inactive and low-intensity, intense, and critically intense. The feature extraction process was performed based on the occurrence of an AE event. It started with a surge across a threshold and lasted as long as the signal did not cross the threshold for a specified duration. During those two instances, various values were recorded, such as how many times the threshold had been crossed, the maximum amplitude, the rise time, the event length, and the signal energy. After the event evaluation and detection steps, if the result turned out to be consistent in terms of timestamp, the source localization was consequently performed. The hardware platform was incorporated with the IEEE 802.15.4 radio module for wireless communication in the band of $2.4 \mathrm{GHz}$. The standard features included a communication range in the order of a hundred meters with a typical power consumption of $50 \mathrm{~mW}$ and a data rate of $250 \mathrm{kbps}$. The system was also deployed with an ad hoc topology where multiple AEpods were placed at strategic places where cracks were most likely to occur on a bridge. This approach promoted great flexibility in the deployment as long as the communication range was sufficient. A multi-hop message routing method was implemented for to realize the ad hoc topology using the directed flood routing framework. Based on the type of AE, which resulted from the classification process, only critical events 
in level 4 were multi-hop forwarded to the base station. Insignificant events in level 1 were discarded, whereas significant events in levels 2 and levels 3 were stored on the SD (secure digital) card for a more in-depth examination if an operator needed further queries. The system was compared to a wired system regarding the number of events detected and the average intensity measurement. The results showed that not much difference existed between the two systems. Hence, they justified the system's design philosophy.

Traditional WSNs exhibit regular and predictable behaviors after the deployment, but the environment is always changing dynamically. Therefore, WSNs require some techniques to handle the problem. A machine learning approach emerges as a promising and attractive candidate due to its ability of automated learning without explicit instructions. Odat et al. [16] proposed a unique sensing device for traffic monitoring that utilized various machine-learning based solutions. Besides performing the sensing and estimation tasks, the system wirelessly transmitted its processed results to a sink node to address more complicated inquiries such as the congestion determination, the calculation of optimal path to the destination with the least heavy traffic, or the dynamic traffic light commanding. In this traffic control application, the array of heterogeneous sensors-PIR (passive infrared) sensors and ultrasonic rangefinders-formed a non-intrusive solution and possessed suitable characteristics, such as low cost, reasonable size, efficient power, and environmental friendliness. Furthermore, the two types of sensors chosen acted as complements to each other. Since measurements from the ultrasonic sensor were less noisy than those from PIR sensors, their combination helped mitigate the number of false alarms and missed detections. The layer of PIR sensors imposed an intrinsic distance limitation, which confused the detection for only one long vehicle with multiple vehicles traveling back to back in proximity. Measurements made by ultrasonic rangefinder once again compensated for PIR measurements to obtain more robust vehicle identifications. The system revolved around an ARM Cortex M4 micro controller with $128 \mathrm{~KB}$ of RAM (random access memory). A solar power generation estimation was incorporated through an energy monitoring circuit. This combination was suitable for energy harvesting. The platform provided a nice balance between the estimation requirements and the built-in resources to interface with the required number of heterogeneous sensors. In this application, a running vehicle had an ample amount of parameter signatures which contributed to the high dimensionality problem. Thus, the authors proposed an adaptive algorithm that performed reasonably on unseen data. A wavelet transform handled data denoisaing before the application of any processing algorithms. A nonlinear autoregressive exogenous input neural method was then used to build a network for the ground temperature estimation. The variations in measurement could be observed if there was a difference between the estimated temperature and the actual one from PIR sensors. By cross verification with validation data, the high discrepancies were indicators of the presence of a vehicle within the coverage range of PIR sensors. Therefore, the variations served as inputs to two algorithms for vehicle detection: dynamic Bayesian networks and Gaussian mixture models. The Bayesian Network was also used to address the vehicle classification problem, given the fusion measurements from PIR sensors and ultrasonic rangefinders. A 10W solar panel was used to take advantage of the available ambient energy since the device has been placed at various outdoor locations such as urban streetlights or public street signs. The in-node sensor signal processing largely contributed to a significant reduction in energy consumption compared to direct data forwarding to the sink node Thus, it was greatly beneficial for the system to use the solar panel as a power source. For evaluation, the field tests indicated high accuracy in vehicle detection (99\%), an acceptable error in speed estimation, and adequate accuracy in vehicle classification.

Table 1 depicts various characteristics of a heterogeneous sensor system from the system development viewpoint. In order to build strong and robust heterogeneous sensor systems, a thorough analysis needs to be performed to construct proper sensors, capable hardware platforms, effective sensor fusion processes, and innovative algorithm 
designs. In several designs, machine learning assists heterogeneous sensor systems to resolve obscure situations.

Table 1. Heterogeneous sensor systems with system design features.

\begin{tabular}{lll}
\hline Paper & Conspicuous Features & Field of Application \\
\hline Lambrou et al. [14] & Custom sensor, data fusion, and detection algorithm design & Water contamination detection \\
\hline Ledeczi et al. [15] & $\begin{array}{l}\text { Utilize FPGA, system wakeup using sensor trigger, multi- } \\
\text { hop ad hoc network }\end{array}$ & Civil structural monitoring \\
\hline Odat et al. [16] & Lightweight machine learning algorithms on WSN & $\begin{array}{l}\text { Vehicle classification and speed } \\
\text { estimation }\end{array}$ \\
\hline Han et al. [17] & $\begin{array}{l}\text { Utilize DSP, process sound and magnetic data, ad hoc net- } \\
\text { work }\end{array}$ & $\begin{array}{l}\text { Sound search for robots with col- } \\
\text { laboration }\end{array}$ \\
\hline
\end{tabular}

\subsection{Homogeneous Sensor System}

An array of homogeneous sensors is multiple identical sensors with a duplicated setting and put together in a particular geometric topography to provide the same input data. Systems with an array of homogeneous sensors possess a high number of dimensions of the problem and need to coordinate the sensors for an appropriate collaboration. Those systems are usually associated with the processing of electromagnetic and acoustic signals (Figure 5).

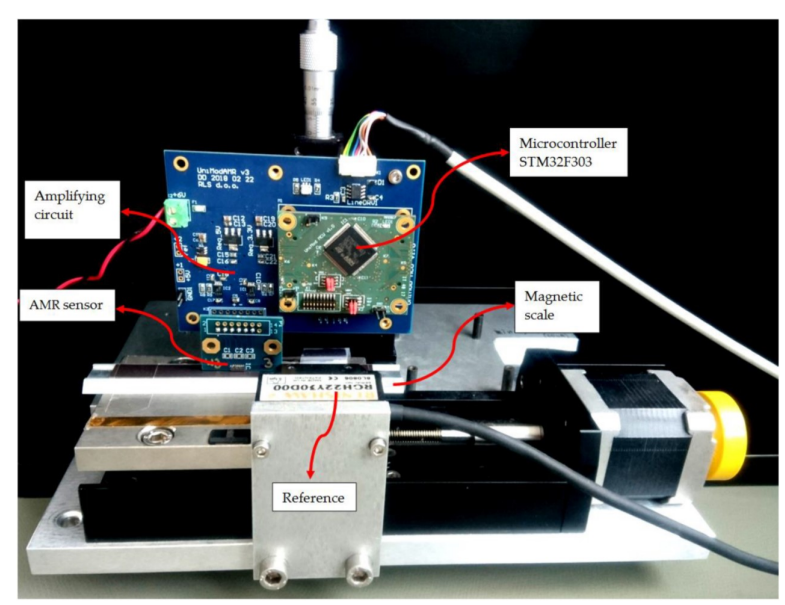

(a)

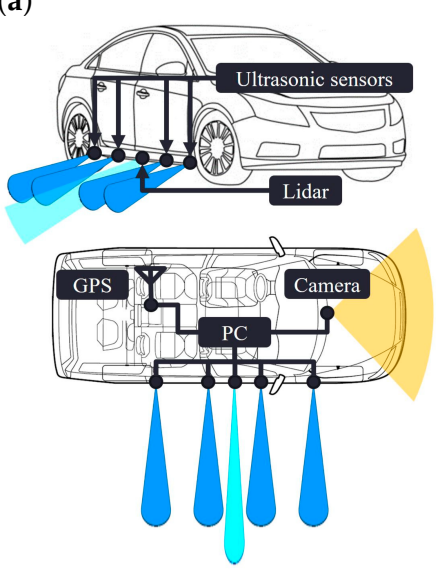

(b)

Figure 5. Usage of homogeneous sensor systems: (a) A system using array of magnetoresistive sensors [18]. (b) A system using array of ultrasonic sensors [19]. 
Applications utilizing homogeneous sensors can have an enhanced coverage range, spread out over the area of interest, and receive more precise measurements. For instance, an array of high-density tunneling magnetoresistance sensors gave a broader and better detection of disturbance in magnetic fields caused by suspected objects [20]. In another design [21], an array of three packaged PZT (packaged piezoelectric transducer) sensors was used in an ultrasonic analysis for the fatigue crack detection. Two PZTs excited two distinguished sinusoidals while the other one performed measurements from the ultrasonic response. The authors attempted to provide a low power device with a convenient deployment. The device could be easily attached to the target structure, and the detection could then be performed autonomously without any past data. The sensor node consisted of four modules, responsible for data sensing, acquiring and processing, communication, and powering. Three channels were present in the excitation/sensing module: one for high frequency (HF) excitation, one for low frequency (LF) excitation, and one sensing channel. The data acquisition/processing module had a combination of FPGA and a micro controller. With its parallel operation nature, the FPGA was perfectly suited for high-speed data logging. The crack detection algorithm was embedded into the micro controller, where most of signal processing tasks were conducted. The two devices both interacted with the ultrasonic data stored on an SRAM (static RAM) memory. The wireless communication module was realized with an off-the-shelf Z1 module, which used the ZigBee standard for low power consumption. Since the node aimed for low power usage, it mainly stayed in the sleep mode and only woke up once every several weeks. A low power timer in the communication module played as the primary system trigger, which allowed the node out of the sleep mode It activated the data/acquisition module and the excitation/sensing module to perform the structure diagnostic algorithm. The detection algorithm was based on the data modulation. A structure applied with two unique frequencies would expose only two original frequencies in case of no damages. On the other hand, if the structure had some fatigue crack, it would manifest harmonics and modulation of the input frequencies. A history data free crack detection algorithm was constructed based on that finding. An ad hoc network was utilized when the system was deployed on the field with the participation of a sink node and relay nodes. The sink node gave an overall look on the whole network operation, and the relay nodes helped for data aggregation. The system used a lithium battery as the primary power source with the consideration to exploit some forms of energy harvesting such as solar power, vibration energy originated from the traffic, and RF-based (radio frequency) wireless energy transmission. The system was thoroughly verified through both a laboratory test and a field test. The deployment outcomes conducted by Non Destructive Testing engineers were used as a confirmation for the detection algorithm implemented on the sensor node. The result justified that the proposed sensor node performed consistently with the validation data. A follow-up design of [21] was later proposed in [22] to harvest low-frequency vibration energy from the bridge, equipping the wireless fatigue crack detector with energy harvesting capability. The system has lengthened battery life up to 2.2 years, thus significantly reducing the maintenance cost.

As with the heterogeneous counterpart, a computing engine can belong to various types, such as DSP or FPGA, to speed up multiple operations. Multimedia data often requires a DSP unit because of its high data volume. The authors in [23] proposed a hand Gesture Recognition System with DSP as the main processing unit and a $434 \mathrm{MHz}$ RF transceiver as the local communication unit. The system performed the palm extraction from image sensors to associate the action with various operations such as interacting with file browsers or manipulating digital libraries. It not only eliminated bulky computing devices, gloves, and makers but also helped to enhance end-user product appreciation. The DSP unit was responsible for conducting the principal duties such as image segmentation, palm extraction, and gesture recognition.

Machine learning, because of its adaptation, outperforms rule-based methods, which are merely built upon a certain threshold level. In [24], the author fed four-second window 
data from six wearable motion sensor units to various machine learning classifiers to distinguish a fall from a daily life activity. Machine learning-based algorithms achieved an accuracy of over $95 \%$ with satisfying computational requirements which made the classifiers applicable for real-time operations.

Table 2 highlights numerous features of homogeneous sensor systems and the gained benefits. Systems with homogeneous sensors might not provide as many features as the ones using heterogeneous sensors, but they are useful in terms of providing intensive details, more precise measurements, and a wide range of coverage. The integration of machine learning algorithms into such systems helps to improve the accuracy of applications.

Table 2. Homogeneous sensor systems with system design features.

\begin{tabular}{lll}
\hline Paper & Conspicuous Features & Field of Application \\
\hline $\begin{array}{l}\text { Liu et al. [21] } \\
\text { Yang et al. [22] }\end{array}$ & $\begin{array}{l}\text { Portable deployment, historical data free operation, } \\
\text { MCU + FPGA, vibration harvesting }\end{array}$ & $\begin{array}{l}\text { Fatigue crack detection on } \\
\text { bridge }\end{array}$ \\
\hline Nikhil et al. [23] & Utilize DSP, eliminate bulky equipments & Gesture recognition \\
\hline Özdemir and Barshan [24] & $\begin{array}{l}\text { Machine learning supported fall detection with high } \\
\text { accuracy }\end{array}$ & Living healthcare \\
\hline Hussain et al. [25] & $\begin{array}{l}\text { Parallel processing by FPGA, hardware software co- } \\
\text { design, reconfigurability, low power, energy efficacy }\end{array}$ & Real-time interferometry system \\
\hline
\end{tabular}

\section{Ad Hoc Network}

An ad hoc network is a multi-hop network where communication is directly performed device-by-device. Other types of network usually require a central gateway. Any network node in ad hoc, on the other hand, can play the role of a gateway. Each node communicates with each other in a peer-to-peer manner without the need for the involvement of a central access point. The ad hoc WSNs are widely used to detect events, to obtain data, and to transmit them to the intended destination for further analysis. The network was previously associated with low range, loss of connection, etc. However, with the advancements in communication technology, more regulatory methods have been improved and laid the foundation for ad hoc wireless network to thrive and deploy on a large scale in a big data era.

The challenges in deploying an ad hoc network are to ensure a balance in network lifetime, coverage, connectivity, and cost. One of the essential concerns in the deployment of WSN is how to balance between network connectivity and network lifetime. Network lifetime usually experiences the biased energy consumption rate (BECR) [26] and is strongly related to the deployment strategy. The BECR issue leads to low energy usage and consequently shortens the network lifetime. The introduction of relay nodes for relaying data helps to bridge the gap between sensor nodes and base stations, which addresses the connectivity issue. Under lifetime constraints, Mhatre et al. [27] proposed a minimum cost scheme while still maintaining connectivity and coverage. The authors utilized type 1 nodes that performed the sensing task and acted as cluster heads to help relay data from sensor nodes (type 0 nodes) to base stations. Nodes were distributed based upon 2D homogeneous Poisson point processes on the area of interest. The analysis result was derived from two strategies: a random deployment and a grid deployment. It suggested that the required number of cluster heads was proportional to the square root of the number of sensor nodes. The utilization helped shrink the average cluster size and mitigate the amount of relaying load on crucial nodes, ensuring a minimum lifetime of the network operation where connectivity and coverage were secured. Xu et al. [28], on the other hand, focused on the effect of a uniform random deployment strategy of relay nodes. Two deployment strategies were proposed to accommodate varied network sizes: the hybrid deployment (with the target of maintaining connectivity and lifetime 
equilibrium) for small network size and the lifetime-oriented deployment for large network size. The lifetime-oriented deployment was related to the distance between nodes and the base station (BS). It enforced higher node density at regions farther from the BS to compensate for higher distance and more energy dissipation. The hybrid deployment consisted of two steps where the first one was ensuring the network lifetime by taking advantage of the lifetime-oriented deployment to arrange specific relay nodes. Then the rest of relay nodes was placed solely for connectivity fulfillment in the region of interest. The combined effect was a uniform deployment that could achieve connectivity-lifetime stability. It served as a reference procedure for effectively deploying relay nodes in an ad hoc manner towards high-volume WSNs. A network of wireless sensors, irrespective of their deployment (whether it is random or structured), experiences a communication gap in their sensing field at the onset. The gap causes the network performance to degrade or creates a communication shortage in certain places. Relay nodes continue to present as the solution to remedy the problem, so the goal of achieving improved communication and extended network lifetime could be feasible. The paper [29] proposed a differential evolution (DE)-based deployment strategy, namely, enhanced lifetime deployment with cost constraints. The architecture contained two layers and two phases of deployment that strived to solve the optimization problem of network lifetime. The deployment started with Multiple Spanning Tree protocol to reach a minimum number of first-phase relay nodes from the network backbone. Using DE optimization method, second-phase relay nodes were then systematically positioned to obtain two objectives: maximizing the network lifetime and preserving a satisfactory degree of connections. The proposed algorithm demonstrated an enhanced network lifetime compared to others, such as the shortest path 3D placement.

Environmental obstacles present as one practical aspect in the deployment of WSNs. Furthermore, many performance aspects such as sensing coverage, node connectivity, and network lifetime are affected by the deployment of WSNs. Thus, environmental obstacles-factors that contribute to the degradation of WSNs-need to be taken into account. Kuawattanaphan et al. [30] proposed a deployment algorithm for WSNs to tackle network coverage, connectivity, and lifetime problems with environmental obstructions as a constituent factor. The solution, namely, DeVForce-AP, was a fusion of two constituting algorithms: the Delaunay triangulation method (D) and the extended virtual force algorithm (eVForce). The adaptive parameter (AP) tuning mechanism was utilized to alter the parameters to various environment schemes in an automated manner. The Delaunay triangulation performed a search and removal of the biggest coverage gap in the region. It was utilized in the first stage of the algorithm. The method then applied the eVForce in its second stage to prevent the effect of environmental obstacles and to keep network connectivity stable. DeVForce-AP required no parameter configuration in advance due to the usage of AP. The results indicated that the proposed scheme exceeded each of the traditional individual deployment and the random deployment. Behaviors of ad hoc WSNs with unreliable nodes have been studied in [31], where general Random Geometric Graphs were used to model nodes with an independent fault mode. A formula was derived for the network breakdown probability with a finite Rayleigh MIMO (multiple-input multipleoutput) model based on the approximation theory. The process also discovered the phase transition phenomena present in model parameters. Making the deployed WSNs tolerant and resilient to node faults is another consideration in the ad hoc network deployment. A reliable network with fault-tolerant capability in [32] was achieved through ideal relay node placement and scheduling. The number of relay nodes was kept at a minimal level, lowering the cost of deployment. However, it still ensured network connectivity and fault resiliency through the utilization of a k-connected graph. Node scheduling, established by a local search scheme, lowered redundancy and provided sufficient network coverage.

In a big data era, nodes in WSNs are deployed with high density and are hard to recharge or replace batteries. Network topology design has significant impact on the node operating time and thus the network lifetime. Since multiple sensor nodes are deployed to 
sense common events, data redundancy will exist to some extent. Data aggregation is a widely adopted method for wireless routing in sensor networks to diminish data redundancy, decrease the number of data transmission, minimize the overall power consumption of the whole network, and prolong the network lifetime [33]. Designing a data aggregation scheme to keep an optimized level of energy consumption and maximize the network lifetime is an interesting and challenging task. Thus, many research efforts have been spent on this topic. Besides obtaining the energy efficiency and lengthening the network lifetime, the utilized data aggregation scheme needs to ensure network scalability in terms of timely packet arrival, preserve data accuracy at an acceptable level, and support collision avoidance [34]. Based on how information flows through nodes, the aggregation mechanisms are classified into routing-based, cluster-based, and machine learning-based mechanisms. Relay routing is a simple yet effective method where data is routed through multi-hop. In order to overcome excessive energy consumption when data is aggregated, the authors in [35] proposed a differentiated data aggregation routing (DDAR) scheme. The target was to selectively direct data that possessed different Quality of Service requirements through various passages to the sink. Aggregation related parameters such as the deadline and the threshold could be configured accordingly without compromising data transmission quality. The DDAR scheme was expanded with an improved version to take advantage of energy leftover in nodes distant from the sink. By properly lowering the deadline and threshold parameters, the strategy could achieve higher energy performance and better delay contraction. In some large scale WSNs with high node density, directly forwarding data from sensor nodes to the sink may overflow all nodes with transmission tasks. In such cases, partitioning the network into clusters, orchestrated by cluster heads for sending aggregated data to base stations, is helpful and advantageous (Figure 6). In [36], Siva Ranjani et at. proposed an energy efficient cluster based data aggregation (ECBDA) scheme with four phases that involved the formation of clusters and the data aggregation. The clustering process was conducted in an on-demand manner in order to prevent the network from high loads of setup message transmission. Clustering techniques helped reduce energy consumption and lower the chances of collision. Data redundancy exists inevitably in WSNs because of the spatiality of sensor nodes, and it is demanded to explore the internal texture of data in a way that best explains the data variance. principal component analysis (PCA) - a dimensionality reduction technique - is effective for machine learning-based WSN data compression. The authors in [37] proposed Adaptive-PCA method that selectively performed PCA depending on the urgency of situations on sensor nodes. PCA was utilized in ordinary circumstances to lower the packet traffic, whereas the sensed data was transmitted immediately to the BS in emergency cases. The method from [38] combined clustering with PCA on cluster heads. The scheme guaranteed energy consumed evenly inside clusters.

Table 3 summarizes ad hoc network problems and proposed solutions based on relay node deployment and data aggregation. Ad hoc networks with the ability to establish communication without central device involvement emerge as a promising topology for WSNs. With proper utilization of relay nodes and data aggregation techniques, ad hoc networks can achieve an equilibrium in network lifetime, range coverage, device connectivity, and low cost. Through adequate scheduling, the networks can also handle environmental obstacles and reach a satisfying level of fault tolerance. 


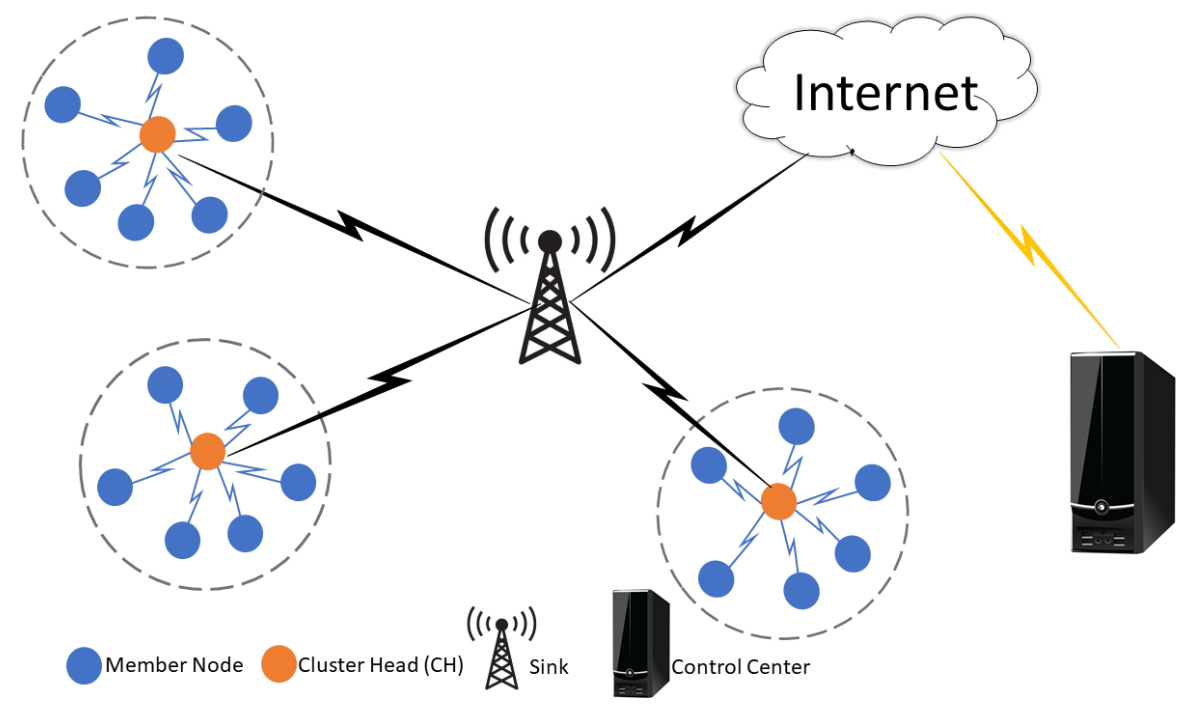

Figure 6. Ad hoc network with cluster head deployment (adapted from [39]).

Table 3. Summary of ad hoc topology problems and solutions.

\begin{tabular}{lll}
\hline Paper & Problem & Solution \\
\hline Mhatre et al. [27] & $\begin{array}{l}\text { Relay node deployment with litetime con- } \\
\text { straints }\end{array}$ & $\begin{array}{l}\text { Do clustering with cluster heads } \\
\text { (CH), optimal number of CHs }\end{array}$ \\
\hline Xu et al. [28] & Balance network lifetime and connectivity & $\begin{array}{l}\text { Hybrid and lifetime-oriented de- } \\
\text { ployments }\end{array}$ \\
\hline Ayinde and Barnawi [29] & $\begin{array}{l}\text { Communication gap at the onset of deploy- } \\
\text { ment }\end{array}$ & $\begin{array}{l}\text { Enhanced Lifetime Deployment } \\
\text { with Cost Constraints based on } \\
\text { DE }\end{array}$ \\
\hline Kuawattanaphan et al. [30] & $\begin{array}{l}\text { Network degeneration by environmental ob- } \\
\text { stacles }\end{array}$ & $\begin{array}{l}\text { DeVForce-AP with parameter } \\
\text { free configuration }\end{array}$ \\
\hline $\begin{array}{l}\text { Suganthi and Sundaram [32] } \\
\text { Network with node faults }\end{array}$ & $\begin{array}{l}\text { Relay node placement and } \\
\text { scheduling by local search }\end{array}$ \\
\hline $\begin{array}{l}\text { Li et al. [35] } \\
\text { Siva Ranjani et al. [36] } \\
\begin{array}{l}\text { Poekaew and Champrasert [37] } \\
\text { Li et al. [38] }\end{array}\end{array}$ & $\begin{array}{l}\text { Data redundancy which increases data trans- } \\
\text { mission and leads to high power consumption }\end{array}$ & Data aggregation \\
\hline
\end{tabular}

\section{Energy Harvesting System}

Energy harvesting is the conversion of energy readily available in the surrounding into usable electrical energy. The general principle of energy harvesting is similar to the one in large-capacity renewable energy generation such as wind turbines; however, the amount of harvested energy is much smaller, with the magnitude in the range of micro to milliwatts $[40,41]$. The widespread usage of WSNs has led to the improvement in energy harvesting since one of the major bottlenecks is the limitation imposed on energy storage. The battery supply scheme suffers from finite capacity, expects periodic replacement or recharging, and raises environmental concerns on battery disposal. Therefore, it is necessary to develop an effective energy harvesting scheme for WSNs in order to overcome the energy constraints and to supplement batteries. The energy subsystem in an energy harvesting node consists of a harvester which performs the conversion. Various available sources for harvesting technology are present in Figure 7. 
Among many energy sources, solar is the most prominent one with three renowned pioneers of solar harvesting wireless sensor nodes: Prometheus [42], Everlast [43], and Heliomote [44]. Various complement techniques have been proposed to increase the efficiency of solar harvesting systems, achieve highest possible power from solar panels, and maximize power conversion under most of the solar conditions. Pulse width modulation (PWM) and maximum power point tracking (MPPT) are two methods in DC-DC converter control units that convert the voltage amplitude to the desired level. In [45], Sharma et al. designed a couple of models for solar energy harvester systems using PWM and MPPT. The results indicated that the MPPT controlled converter had higher efficiency than the PWM controlled one. Li et al. [46], on the other hand, took advantage of both methods. The authors considered MPPT as a remarkedly efficient method to harvest solar energy in the first phase. They then proposed a discontinuous PWM based control so that DC electrical power was employed with higher efficiency, and switching losses during conversion were diminished. Solar harvesting was equipped to gateway and power beacon network components to create a zero-energy wireless-powered sensor networks in [47]. The paper proposed a solar harvesting model with a novel energy allocation algorithm to study the connectivity in clustered wireless-powered sensor networks. Sensor nodes were clustered together to transmit data to a solar-powered gateway and had wireless energy harvesting capability where power was transmitted wirelessly from power beacons. The developed energy allocation algorithm ensured a proper level of the transmission power for beacons and gateways based on the degree of cloud coverage. Mechanical motion-based energy harvesting systems scavenge energy from vibrations, and those types of energy can be appropriate for traffic-related applications or intrusion detection systems. In [48], the authors performed an investigation on energy stemmed from a train-induced vibrations, and recorded that the maximum amount of harvested energy was $0.25 \mathrm{~J} / \mathrm{kg}$ at the frequency of $17 \mathrm{~Hz}$. A study from [49] suggested that road pavement designs could be equipped with mechanical energy harvesting capability thanks to vehicular load. That type of harvested energy provided power for sensor systems and acted as a trigger signal for waking up low power systems and performing monitoring tasks. Another study [50] demonstrated the recognition for a vibration-based piezoelectric energy harvester to be deployed in WSNs under weak vibration circumstances for intelligent environment-monitoring applications. The proposed system was designed with an energy management module accompanied by the ability to perform self-regulation, self-power, and self-control. The system achieved a power transfer efficiency of $42 \%$, required no external power, and spawned a regulated voltage of $3.3 \mathrm{~V}$ for the system operation. In wearable devices, energy harvesting from human activities can eliminate the necessity of bulky battery and the need for replacement. As a result, users can possess a device in a smaller form factor with more comfortability, while the device offers a maintenance-free operation, further increasing pleasant experience. An electromagnetic energy harvester was designed in [51] based on body motion characteristics, specifically suited to running and walking actions. The sensing rate was adapted to jogger activities, which in turn altered the transmission interval. With those features, the life of the batteryless sensor node was further extended. The construction of the system justified the feasibility of a wearable energy harvesting sensor network. Another type of energy harvesting technique that gains more attention recently is the wireless power transfer. The technology can scavenge energy from ambient radio-frequency signal radiation. The energy is intrinsic in electromagnetic waves through the electric field and the magnetic field. In [52], Kim et al. examined and developed a self-sustaining wireless platform, and benchmarked through a batteryless embedded micro controllerenabled sensor platform. The ambient wireless energy had lower density than that from other sources. By duty cycling the system optimally, however, the wireless harvester could provide the WSNs with sufficient power for self-sustainable operability. Wireless energy harvesters play an essential role as the key technology in self-operating and sustainable systems from numerous fields, including IoT, artificial smart skins, implantable medical devices, etc. 


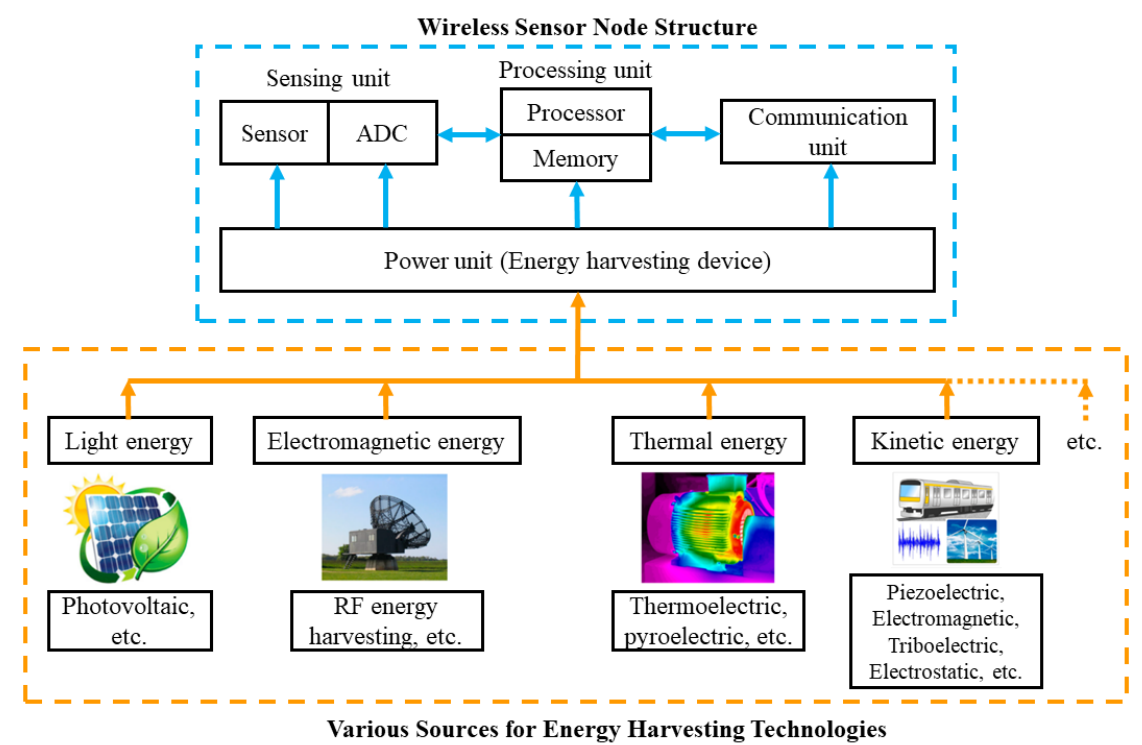

Figure 7. Sources for energy harvesting (adapted from [53]) (the blue line encompasses the WSN structure, and orange line indicates various sources used for energy harvesting).

As shown in Figure 8, there are two main groups for energy harvesting systems based on how they utilize the harvested energy: (a) one without storage where the converted electrical energy powers sensor nodes directly and (b) the one with storage in the form of a supercapacitor or rechargeable battery where the converted energy is put into storage before it is used to drive a sensor node [54]. Supercapacitors have particular features suitable for power buffering, such as low equivalent series resistance (ESR) for high power delivery, low leakage current for conserving the low charge current, and simple charging [55]. On the other hand, rechargeable batteries, which are based on reversible electrochemical reactions for energy restoration, have higher energy density and more maturity. Sensor nodes can apply the energy harvesting storage in three different ways depending on the requirements. The first two ways are to use supercapacitors and rechargeable batteries separately while the third one is to combine both storage types. Supercapacitors-based systems are applicable for low power and compact applications, whereas systems with rechargeable batteries are suited to long-lived and task exhaustive cases. Hybrid systems that combine the two storage models experience lower leakage power while keeping a close ESR [56].
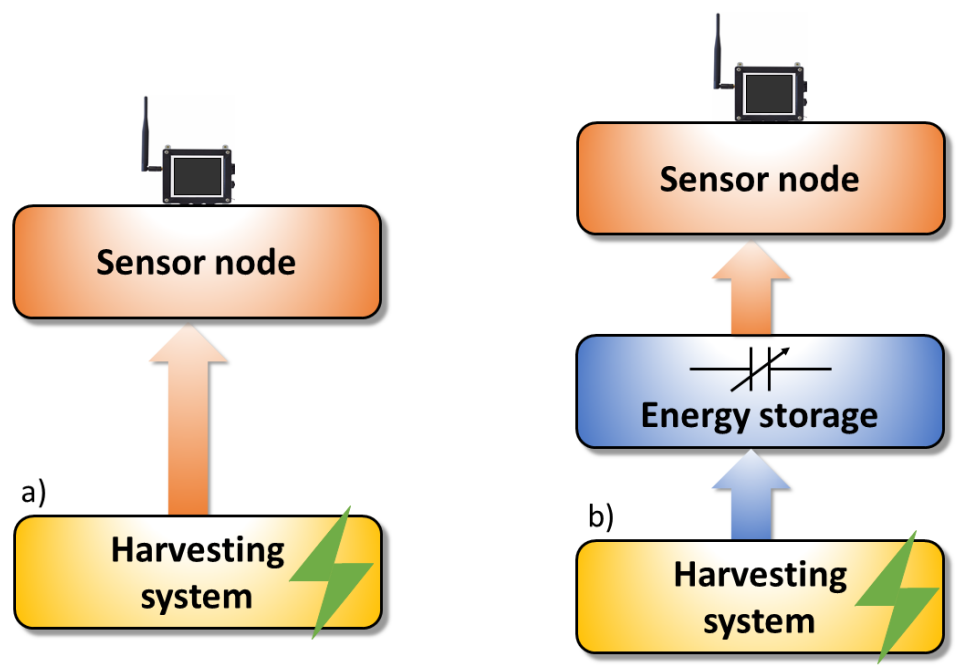

Figure 8. Energy harvesting usage (a) use after harvesting (b) use from storage (adapted from [57]). 
It is important to apply in-node control mechanisms since wireless sensor nodes are distributed in a widely spaced and ad hoc manner. The goals are to maximize throughput and minimize energy consumption so that the energy efficiency of the whole network can be improved. In [58], the authors proposed a distributed control algorithm for nodes in Energy Harvesting Wireless Sensor Networks (EH-WSNs). Using the algorithm, the nodes could dynamically administer their usable harvested energy and subsequently adjust the source rates to seek for maximized link capacity utilization. The authors in [59] leveraged residual energy by utilizing cooperative transmission to limit sensor failures and maintain network functionalities. The joint design of relay selection and power control helped obtain residual energy balance in EH-WSNs. In that case, optimal relays that possessed the highest residual energy could cooperate with the data transmission source. Derived from the adaptive control theory result, the authors in [60] designed an adaptive duty-cycling mechanism for nodes in EH-WSNs. Under the control scheme, sensor nodes adapted to the changes in environmental conditions to maintain their energy-neutral operation efficiently.

Since energy sources for harvesting energy exhibit great variability due to dynamics in the environment, machine learning techniques prove to be a promising tool to ensure an autonomous long-life EH-WSN. In [61], the authors tackled the solar irradiance forecasting problem with five different models to provide reliable solar radiation knowledge and facilitate the development of long-life self-operating sensor nodes. The five models applied the supervised learning and performed regression to predict future solar irradiance from the historical solar intensity dataset. The models provided precise solar irradiance predictions for two days in advance independent of seasonal diversity. Another prediction algorithm, namely, Q-learning-based solar energy prediction (QL-SEP), was proposed in [62] to deal with the un-controllability of solar energy sources. Q-learning is a technique that gives future predictions relying on information in the past [63] and is a reinforcement learning algorithm. QL-SEP performed stronger with the additional information regarding current weather conditions and led to optimal energy allocation among nodes in EH-WSN. The author in [64] proposed a reinforcement learning-based two-stage sleep scheduling algorithm for sustainable operation in every time slot. Initially, a precedence operatorbased group formation algorithm was performed to establish and secure adequate area coverage and required entire nodes to participate in the process. Q-learning was then applied to the node selection algorithm to impose nodes on collaborative learning and environment adaptation. The combined effect of two algorithms was to create role changes of active nodes, producing the team learning of sleep scheduling. Reinforcement learning is a widely applied technique in machine learning for EH-WSNs because it attempts to make a suitable action to maximize the reward in a particular situation. In EH-WSN, the reward is the optimal energy for various environmental conditions to ensure energy-neutral operation. The authors in [65] employed reinforcement learning with fuzzy reward (RLFR) to cope with ambiguity and uncertainty of EH-WSNs. The usage of RLFR dynamic power management not only resulted in satisfying energy neutrality but also improved energy utilization. Another dynamic power management method was proposed in [66] to fulfill the throughput need of EH-WSN. A learning process was applied to assess how Throughput on Demand requests were served through continuous supervision of environmental conditions, and then perform a corresponding adjustment to the duty cycle for energy neutrality. The method achieved $10.7 \%$ of throughput improvement along with $7.4 \%$ of residual battery energy enhancement. In $[67,68]$, the authors proposed a reinforcement learning-based energy management algorithm named RLMan with low computational and memory footprint. The algorithm was not only suitable for real-time in-node execution but also robust to variabilities of node energy consumption.

This section explores various energy harvesting sources, how they are utilized, and numerous energy storage types. The network perspective facilitates EH-WSN for more energy efficiency through flow control, duty cycling, and cooperative transmission. Various techniques that integrate machine learning, especially reinforcement learning, into EHWSNs for better energy prediction and utilization are also present. 


\section{Discussion}

A huge number of sensors devices in a highly connected world demands an appropriate strategy for selecting right sensor types, connectivity scheme, and energy harvesting capability. Depending on the application requirements and user needs, a proper selection of sensors is utilized to fulfill the system level application specifications. For heterogeneous sensor systems, multiple sensors of different types are used for diverse physical measurements, a wide range of accuracies, and different data rates. On the other hand, the usage of homogeneous sensor systems thrives when the system of interest requires a wide range of detection areas and a low possibility of false triggers. Ad hoc topology is a promising solution for networking in WSNs to reduce the deployment cost of high-end and pricey central devices. It can achieve a balance in lifetime, coverage, and connectivity by applying relay nodes and data aggregation methods. Environmental obstacle-related fault tolerance can be enhanced by using adequate scheduling. Energy harvesting is a necessary feature to construct an automated and long-term operated WSN. Sources for energy harvesting are numerous and omnipresent and requires a proper storage. Combining with network topology, the efficiency of the energy conversion process could be improved through various techniques such as flow control, duty cycling, and cooperative transmission. Many sensor systems have been constructed to take advantages of sensor capability, network connectivity, and energy harvesting features. [69] proposed a WSN that used ad hoc network with solar energy harvesting, exerted 25\% duty cycle for operation while improving network throughput and maximizing WSN network lifetime (20 times increase compared to non-energy harvesting solution). [70] utilized cluster heads and a mobile sink to ensure high performance and overcome energy imbalance, network outages. Yu et al. [71] combined network knowledge and harvesting strategy to minimize the energy consumption in each sensor node. To facilitate reliable data transmission, authors in [72] proposed a stability-aware geographic routing for EH-WSN. The method introduced a better average energy consumption when the transmission ranges and number of nodes changes. The stability problem was addressed in [73] by the combination of data rate and energy management in EH-WSN.

\section{Conclusions}

Several papers which proposed and built array of sensor systems have been reviewed. We also explored some systems with ad hoc topology or with an energy harvesting mechanism. We identified the needs and the challenges in combining the appropriate sensor type with proper networking strategy and energy harvesting technique. Therefore, this review paper serves as a supporting tool for researchers to build wireless sensor nodes that not only fit to applications through the wise selection of sensor array but also operate intelligently when managing power and data transmission.

With the rapid progress in technology, more advanced sensor types, such as nanotechnologybased ones, will arise with less power consumption, more sensitivity, and energy harvesting capability. People will have a wide range of sensor selections and can refer to this work as a handy guide for determining proper solutions. Low power sensor devices give the processing components to operate at their leisure and reduce power consumption as needed. The combination of more advanced sensors and a carefully designed algorithm for system operations can further reduce power consumption of a WSN. More efficient harvesting techniques have been discovered with higher conversion ratios. Those factors lead to low powered, perpetually and efficiently operated devices, reducing the costs of maintenance and replacement.

Author Contributions: Conceptualization and methodology, L.-w.K.; data curation, P.D.N.; funding acquisition, L.-w.K.; investigation, P.D.N.; supervision, L.-w.K.; visualization, P.D.N.; writingoriginal draft, P.D.N.; writing - review and editing, L.-w.K. All authors have read and agreed to the published version of the manuscript.

Funding: This research was funded by Korea Electric Power Corporation, grant number R18XA02. 
Conflicts of Interest: The authors declare no conflict of interest.

\section{References}

1. United Nations, Department of Economic and Social Affairs, Population Division. World Population Prospects. 2019. Available online: https://population.un.org/wpp/Download/Standard/Population/ (accessed on 30 December 2020 ).

2. National Cable \& Telecommunications Association/NCTA-The Internet \& Television Association, United States. Behind the Numbers: Growth in the Internet of Things. Available online: https://www.ncta.com/whats-new/behind-the-numbers-growthin-the-internet-of-things (accessed on 31 December 2020).

3. Adu-Manu, K.; Tapparello, C.; Heinzelman, W.; Katsriku, F.; Abdulai, J.D. Water Quality Monitoring Using Wireless Sensor Networks: Current Trends and Future Research Directions. ACM Trans. Sens. Netw. 2017, 13, 1-41. [CrossRef]

4. Singh, A.; Kumar, S.; Kaiwartya, O. A Hybrid Localization Algorithm for Wireless Sensor Networks. In Proceedings of the 3rd International Conference on Recent Trends in Computing 2015 (ICRTC-2015), Ghaziabad, India, 12-13 March 2015; Volume 57, [CrossRef]

5. Guruprasad, S.; Bisnath, S.; Lee, R.; Kozinski, J. Design and implementation of a low-cost SoC-based software GNSS receiver. IEEE Aerosp. Electron. Syst. Mag. 2016, 31, 14-19. [CrossRef]

6. Gutiérrez, J.; Villa-Medina, J.F.; Nieto-Garibay, A.; Porta-Gándara, M.A. Automated Irrigation System Using a Wireless Sensor Network and GPRS Module. IEEE Trans. Instrum. Meas. 2014, 63, 166-176.

7. Majumder, S.; Mondal, T.; Deen, M.J. Wearable Sensors for Remote Health Monitoring. Sensors 2017, 17, 130. [CrossRef]

8. Vavrinsky, E.; Subjak, J.; Donoval, M.; Wagner, A.; Zavodnik, T.; Svobodova, H. Application of Modern Multi-Sensor Holter in Diagnosis and Treatment. Sensors 2020, 20. [CrossRef]

9. Bouain, M.; Ali, K.; Berdjag, D.; Fakhfakh, N.; Atitallah, R. An Embedded Multi-Sensor Data Fusion Design for Vehicle Perception Tasks. J. Commun. 2018, 13, 8-14. [CrossRef]

10. Giacalone, J.; Bourgeois, L.; Ancora, A. Challenges in aggregation of heterogeneous sensors for Autonomous Driving Systems. In Proceedings of the 2019 IEEE Sensors Applications Symposium (SAS), Sophia Antipolis, France, 11-13 March 2019; pp. 1-5.

11. Nguyen, P.D.; Vo, H.Q.; Le, L.N.; Eo, S.; Kim, L. An IoT Hardware Platform Architecture for Monitoring Power Grid Systems based on Heterogeneous Multi-Sensors. Sensors 2020, 20. [CrossRef]

12. Bartsch, M.S.; Federle, W.; Full, R.J.; Kenny, T.W. Small insect measurements using a custom MEMS force sensor. In Proceedings of the TRANSDUCERS '03, 12th International Conference on Solid-State Sensors, Actuators and Microsystems, Digest of Technical Papers (Cat. No.03TH8664), Boston, MA, USA, 8-12 June 2003; Volume 2, pp. 1039-1042.

13. Shih, B.; Drotman, D.; Christianson, C.; Huo, Z.; White, R.; Christensen, H.I.; Tolley, M.T. Custom soft robotic gripper sensor skins for haptic object visualization. In Proceedings of the 2017 IEEE/RSJ International Conference on Intelligent Robots and Systems (IROS), Vancouver, BC, Canada, 24-28 September 2017; pp. 494-501.

14. Lambrou, T.P.; Anastasiou, C.C.; Panayiotou, C.G.; Polycarpou, M.M. A Low-Cost Sensor Network for Real-Time Monitoring and Contamination Detection in Drinking Water Distribution Systems. IEEE Sens. J. 2014, 14, 2765-2772. [CrossRef]

15. Ledeczi, A.; Hay, T.; Volgyesi, P.; Hay, D.R.; Nadas, A.; Jayaraman, S. Wireless Acoustic Emission Sensor Network for Structural Monitoring. IEEE Sens. J. 2009, 9, 1370-1377. [CrossRef]

16. Odat, E.; Shamma, J.S.; Claudel, C. Vehicle Classification and Speed Estimation Using Combined Passive Infrared/Ultrasonic Sensors. IEEE Trans. Intell. Transp. Syst. 2018, 19, 1593-1606. [CrossRef]

17. Han, L.; Shen, Z.; Fu, C.; Liu, C. Design and Implementation of Sound Searching Robots in Wireless Sensor Networks. Sensors 2016, 16, 1550. [CrossRef] [PubMed]

18. Domajnko, D.; Križaj, D. Lagging-Domain Model for Compensation of Hysteresis of xMR Sensors in Positioning Applications. Sensors 2018, 18, 2281. [CrossRef]

19. Rhee, J.H.; Seo, J. Low-Cost Curb Detection and Localization System Using Multiple Ultrasonic Sensors. Sensors 2019, 19, 1389. [CrossRef] [PubMed]

20. Gao, J.; Wang, J.; Zhang, L.; Yu, Q.; Huang, Y.; Shen, Y. Magnetic Signature Analysis for Smart Security System Based on TMR Magnetic Sensor Array. IEEE Sens. J. 2019, 19, 3149-3155. [CrossRef]

21. Liu, P.; Lim, H.J.; Yang, S.; Sohn, H.; Lee, C.H.; Yi, Y.; Kim, D.; Jung, J.; Bae, I.H. Development of a "stick-and-detect" wireless sensor node for fatigue crack detection. Struct. Health Monit. 2017, 16, 153-163. [CrossRef]

22. Yang, S.; Jung, S.Y.; Kim, K.; Liu, P.; Lee, S.; Kim, J.; Sohn, H. Development of a tunable low-frequency vibration energy harvester and its application to a self-contained wireless fatigue crack detection sensor. Struct. Health Monit. 2019, 18, 920-933. [CrossRef]

23. Nikhil, S.; Mohan, S.; Ramya, B.; Kadambi, G.R. Design and development of a DSP processor based reconfigurable hand Gesture Recognition System for real time applications. In Proceedings of the 2010 International Conference on Signal and Image Processing, Chennai, India, 15-17 December 2010; pp. 39-44. [CrossRef]

24. Özdemir, A.T.; Barshan, B. Detecting Falls with Wearable Sensors Using Machine Learning Techniques. Sensors 2014, 14, 10691-10708. [CrossRef] [PubMed]

25. Hussain, T.; Amin, S.; Zabit, U.; Bernal, O.D.; Bosch, T. A high performance real-time Interferometry Sensor System Architecture. Microprocess. Microsyst. 2019, 64, 23-33. [CrossRef]

26. Younis, O.; Fahmy, S. HEED: A hybrid, energy-efficient, distributed clustering approach for ad hoc sensor networks. IEEE Trans. Mob. Comput. 2004, 3, 366-379. [CrossRef] 
27. Mhatre, V.P.; Rosenberg, C.; Kofman, D.; Mazumdar, R.; Shroff, N. A minimum cost heterogeneous sensor network with a lifetime constraint. IEEE Trans. Mob. Comput. 2005, 4, 4-15.

28. Xu, K.; Hassanein, H.; Takahara, G.; Wang, Q. Relay Node Deployment Strategies in Heterogeneous Wireless Sensor Networks. IEEE Trans. Mob. Comput. 2010, 9, 145-159.

29. Ayinde, B.O.; Barnawi, A.Y. Differential evolution based deployment of wireless sensor networks. In Proceedings of the 2014 IEEE/ACS 11th International Conference on Computer Systems and Applications (AICCSA), Doha, Qatar, 10-14 November 2014; pp. 131-137.

30. Kuawattanaphan, R.; Champrasert, P.; Aramkul, S. A Novel Heterogeneous Wireless Sensor Node Deployment Algorithm With Parameter-Free Configuration. IEEE Access 2018, 6, 44951-44969. [CrossRef]

31. Takabe, S.; Wadayama, T. Approximation Theory for Connectivity of Ad Hoc Wireless Networks With Node Faults. IEEE Wirel. Commun. Lett. 2019, 8, 1240-1243. [CrossRef]

32. Suganthi, K.; Sundaram, V.B. A constraint based relay node deployment in heterogeneous wireless sensor networks for lifetime maximization. In Proceedings of the 2012 Fourth International Conference on Advanced Computing (ICoAC), Chennai, India, 13-15 December 2012; pp. 1-6.

33. Dhand, G.; Tyagi, S. Data Aggregation Techniques in WSN:Survey. Procedia Comput. Sci. 2016, 92, 378-384. [CrossRef]

34. Geethapriya, K.P.; Kala, I.; Karthik, S. A study on data aggregation scheme over wireless sensor network. In Proceedings of the 2016 10th International Conference on Intelligent Systems and Control (ISCO), Coimbatore, India, 7-8 January 2016; pp. 1-5.

35. Li, X.; Liu, W.; Xie, M.; Liu, A.; Zhao, M.; Xiong, N.N.; Zhao, M.; Dai, W. Differentiated Data Aggregation Routing Scheme for Energy Conserving and Delay Sensitive Wireless Sensor Networks. Sensors 2018, 18, 2349. [CrossRef] [PubMed]

36. Siva Ranjani, S.; Radha Krishnan, S.; Thangaraj, C. Energy-efficient Cluster Based Data Aggregation for Wireless Sensor Networks. In Proceedings of the 2012 International Conference on Recent Advances in Computing and Software Systems, Chennai, India, 25-27 April 2012; pp. 174-179.

37. Poekaew, P.; Champrasert, P. Adaptive-PCA: An event-based data aggregation using principal component analysis for WSNs. In Proceedings of the 2015 International Conference on Smart Sensors and Application (ICSSA), Kuala Lumpur, Malaysia, 26-28 May 2015; pp. 50-55.

38. Li, J.; Guo, S.; Yang, Y.; He, J. Data Aggregation with Principal Component Analysis in Big Data Wireless Sensor Networks. In Proceedings of the 2016 12th International Conference on Mobile Ad-Hoc and Sensor Networks (MSN), Hefei, China, 16-18 December 2016; pp. 45-51. [CrossRef]

39. Anzola, J.; Pascual, J.; Tarazona, G.; González Crespo, R. A Clustering WSN Routing Protocol Based on k-d Tree Algorithm. Sensors 2018, 18, 2899. [CrossRef]

40. Tom J. Kaźmierski, S.B. Energy Harvesting Systems Principles, Modeling and Applications, 1st ed.; Springer: New York, NY, USA, 2010.

41. Kirstein, T. Multidisciplinary Know-How for Smart-Textiles Developers; Woodhead Publishing: Cambridge, UK, 2013.

42. Jiang, X.; Polastre, J.; Culler, D. Perpetual environmentally powered sensor networks. In Proceedings of the IPSN 2005, Fourth International Symposium on Information Processing in Sensor Networks, Los Angeles, CA, USA, 24-27 April 2005 ; pp. 463-468.

43. Simjee, F.I.; Chou, P.H. Efficient Charging of Supercapacitors for Extended Lifetime of Wireless Sensor Nodes. IEEE Trans. Power Electron. 2008, 23, 1526-1536. [CrossRef]

44. Raghunathan, V.; Kansal, A.; Hsu, J.; Friedman, J.; Mani, S. Design considerations for solar energy harvesting wireless embedded systems. In Proceedings of the IPSN 2005, Fourth International Symposium on Information Processing in Sensor Networks, Los Angeles, CA, USA, 24-27 April 2005; pp. 457-462.

45. Sharma, H.; Haque, A.; Jaffery, Z.A. Modeling and Optimisation of a Solar Energy Harvesting System for Wireless Sensor Network Nodes. J. Sens. Actuator Netw. 2018, 7, 40. [CrossRef]

46. Li, L.; Wang, H.; Chen, X.; Bukhari, A.A.S.; Cao, W.; Chai, L.; Li, B. High Efficiency Solar Power Generation with Improved Discontinuous Pulse Width Modulation (DPWM) Overmodulation Algorithms. Energies 2019, 12, 1765. [CrossRef]

47. Mekikis, P.; Kartsakli, E.; Antonopoulos, A.; Alonso, L.; Verikoukis, C. Connectivity Analysis in Clustered Wireless Sensor Networks Powered by Solar Energy. IEEE Trans. Wirel. Commun. 2018, 17, 2389-2401. [CrossRef]

48. Gatti, G.; Brennan, M.; Tehrani, M.; Thompson, D. Harvesting energy from the vibration of a passing train using a single-degreeof-freedom oscillator. Mech. Syst. Signal Process. 2016, 66-67, 785-792. [CrossRef]

49. Chen, Y.; Zhang, H.; Zhang, Y.; Li, C.; Yang, Q.; Zheng, H.; Lu, C. Mechanical Energy Harvesting From Road Pavements Under Vehicular Load Using Embedded Piezoelectric Elements. J. Appl. Mech. 2016, 83, 081001. [CrossRef]

50. Han, Y.; Feng, Y.; Yu, Z.; Lou, W.; Liu, H. A Study on Piezoelectric Energy-Harvesting Wireless Sensor Networks Deployed in a Weak Vibration Environment. IEEE Sens. J. 2017, 17, 6770-6777. [CrossRef]

51. Chamanian, S.; Uluşan, H.; Özge, Z.; Baghaee, S.; Uysal-Biyikoglu, E.; Külah, H. Wearable battery-less wireless sensor network with electromagnetic energy harvesting system. Sens. Actuators A Phys. 2016, 249, 77-84. [CrossRef]

52. Kim, S.; Vyas, R.; Bito, J.; Niotaki, K.; Collado, A.; Georgiadis, A.; Tentzeris, M.M. Ambient RF Energy-Harvesting Technologies for Self-Sustainable Standalone Wireless Sensor Platforms. Proc. IEEE 2014, 102, 1649-1666. [CrossRef]

53. Tang, X.; Wang, X.; Cattley, R.; Gu, F.; Ball, A.D. Energy Harvesting Technologies for Achieving Self-Powered Wireless Sensor Networks in Machine Condition Monitoring: A Review. Sensors 2018, 18, 4113. [CrossRef]

54. Shaikh, F.K.; Zeadally, S. Energy harvesting in wireless sensor networks: A comprehensive review. Renew. Sustain. Energy Rev. 2016, 55, 1041-1054. [CrossRef] 
55. Weddell, A.S.; Merrett, G.V.; Kazmierski, T.J.; Al-Hashimi, B.M. Accurate Supercapacitor Modeling for Energy Harvesting Wireless Sensor Nodes. IEEE Trans. Circuits Syst. II Express Briefs 2011, 58, 911-915. [CrossRef]

56. Wang, W.; Wang, N.; Vinco, A.; Siddique, R.; Hayes, M.; O'Flynn, B.; O'Mathuna, C. Super-capacitor and Thin Film Battery Hybrid Energy Storage for Energy Harvesting Applications. J. Phys. Conf. Ser. 2013, 476, 012105. [CrossRef]

57. Fahmy, H.M.A. Energy Harvesting in WSNs. In Wireless Sensor Networks: Energy Harvesting and Management for Research and Industry; Springer: Berlin/Heidelberg, Germany, 2020; pp. 41-99. [CrossRef]

58. Frezzetti, A.; Manfredi, S. Design and experimental testing of an optimization-based flow control algorithm for Energy Harvesting Wireless Sensor Networks. Control. Eng. Pract. 2019, 92, 104075. [CrossRef]

59. Zhang, D.; Chen, Z.; Zhou, H.; Chen, L.; Shen, X. Energy-balanced cooperative transmission based on relay selection and power control in energy harvesting wireless sensor network. Comput. Netw. 2016, 104, 189-197. [CrossRef]

60. Vigorito, C.M.; Ganesan, D.; Barto, A.G. Adaptive Control of Duty Cycling in Energy-Harvesting Wireless Sensor Networks. In Proceedings of the 2007 th Annual IEEE Communications Society Conference on Sensor, Mesh and Ad Hoc Communications and Networks, San Diego, CA, USA, 18-21 June 2007; pp. 21-30.

61. Sharma, A.; Kakkar, A. Forecasting daily global solar irradiance generation using machine learning. Renew. Sustain. Energy Rev. 2018, 82, 2254-2269. [CrossRef]

62. Kosunalp, S. A New Energy Prediction Algorithm for Energy-Harvesting Wireless Sensor Networks With Q-Learning. IEEE Access 2016, 4, 5755-5763. [CrossRef]

63. Connell, J.H.; Mahadevan, S. ROBOT LEARNING. Robotica 1999, 17, 229-235.

64. Chen, H.; Li, X.; Zhao, F. A Reinforcement Learning-Based Sleep Scheduling Algorithm for Desired Area Coverage in SolarPowered Wireless Sensor Networks. IEEE Sens. J. 2016, 16, 2763-2774. [CrossRef]

65. Liu, C.; Hsu, R.C. Dynamic power management utilizing reinforcement learning with fuzzy reward for energy harvesting wireless sensor nodes. In Proceedings of the IECON 2011-37th Annual Conference of the IEEE Industrial Electronics Society, Melbourne, Victoria, Australia, 7-10 November 2011; pp. 2365-2369.

66. Hsu, R.C.; Liu, C.; Wang, H. A Reinforcement Learning-Based ToD Provisioning Dynamic Power Management for Sustainable Operation of Energy Harvesting Wireless Sensor Node. IEEE Trans. Emerg. Top. Comput. 2014, 2, 181-191. [CrossRef]

67. Aoudia, F.A.; Gautier, M.; Berder, O. Learning to survive: Achieving energy neutrality in wireless sensor networks using reinforcement learning. In Proceedings of the 2017 IEEE International Conference on Communications (ICC), Paris, France, 21-25 May 2017; pp. 1-6.

68. Ait Aoudia, F.; Gautier, M.; Berder, O. RLMan: An Energy Manager Based on Reinforcement Learning for Energy Harvesting Wireless Sensor Networks. IEEE Trans. Green Commun. Netw. 2018, 2, 408-417. [CrossRef]

69. Sharma, H.; Haque, A.; Jaffery, Z.A. Maximization of wireless sensor network lifetime using solar energy harvesting for smart agriculture monitoring. Ad Hoc Netw. 2019, 94, 101966. [CrossRef]

70. Son, Y.; Kang, M.; Kim, Y.; Yoon, I.; Noh, D.K. Energy-Efficient Cluster Management Using a Mobile Charger for Solar-Powered Wireless Sensor Networks. Sensors 2020, 20, 3668. [CrossRef]

71. Yu, C.M.; Tala't, M.; Chiu, C.H.; Huang, C.Y. Joint Balanced Routing and Energy Harvesting Strategy for Maximizing Network Lifetime in WSNs. Energies 2019, 12, 2336. [CrossRef]

72. Hieu, T.D.; Dung, L.T.; Kim, B.S. Stability-Aware Geographic Routing in Energy Harvesting Wireless Sensor Networks. Sensors 2016, 16, 696. [CrossRef] [PubMed]

73. Ashraf, N.; Christofides, N.; Lestas, M. Combined Data Rate and Energy Management in Wireless Sensor Networks with Energy Harvesting Capability. In Proceedings of the 2018 IEEE Conference on Decision and Control (CDC), Miami, FL, USA, 17-19 December 2018; pp. 6717-6722. [CrossRef] 